\title{
PENGARUH KEPADATAN DAN DURASI DALAM KONDISI TRANSPORTASI SISTEM KERING TERHADAP KELULUSAN HIDUP LOBSTER AIR TAWAR (Cherax quadricarinatus)
}

\author{
Theresia Dwi Suryaningrum*), Diah Ikasari*), dan Syamdidi*)
}

\begin{abstract}
ABSTRAK
Penelitian transportasi lobster air tawar hidup sistem kering dengan perlakuan kepadatan dan durasi dalam kondisi transportasi terhadap kelulusan hidup lobster telah dilakukan. Sebelum dikemas, lobster dipingsankan secara langsung dengan memasukkan ke dalam air dingin suhu $12^{\circ} \mathrm{C}$ selama 45 menit. Lobster kemudian dikemas dalam kotak plastik yang dialasi dengan spons basah dengan kepadatan bervariasi (masing-masing 6 dan 8 ekor lobster ukuran 35-50 g/ekor dalam setiap kotak plastik). Kotak plastik kemudian dimasukkan ke dalam kotak styrofoam yang masing-masing kotak diisi dengan 6 kotak plastik. Lobster ditransportasikan dengan mobil dari Jakarta ke Lampung, pada hari ke-4 kembali ke Jakarta dan diamati pada hari ke-5, 6, dan 7. Pengamatan dilakukan terhadap penurunan bobot lobster dan kelulusan hidup lobster dengan mencatat mortalitasnya setelah dibugarkan kembali selama 1 hari. Hasil penelitian menunjukkan bahwa kepadatan berpengaruh terhadap menurunnya tingkat kelulusan hidup dan bobot lobster selama dalam kondisi transportasi. Kemasan dengan kepadatan 6 ekor/kotak plastik menghasilkan kelulusan hidup yang lebih baik dibandingkan dengan kemasan dengan kepadatan 8 ekor/kotak plastik. Semakin lama waktu dalam kondisi transportasi, semakin rendah kelulusan hidup dan bobot lobster. Durasi dalam kondisi transportasi sampai 7 hari dapat menurunkan bobot lobster sampai $10 \%$. Transportasi lobster dengan kepadatan 6 ekor/kotak plastik selama 6 hari menghasilkan kelulusan hidup $97 \%$ dan tetap sehat setelah dibugarkan kembali. Oleh karena itu, lobster air tawar sebaiknya ditransportasikan dengan durasi tidak lebih dari 6 hari.
\end{abstract}

ABSTRACT: Effect of density and duration under dry system transportation condition on the survival rate of freshwater lobster (Cherax quadricarinatus). By: Theresia Dwi Suryaningrum, Diah Ikasari and Syamdidi

Research on the freshwater lobster dry system transportation has been carried out to study the effects of density and duration under transportation condition on the survival rate. Lobsters were cold shocked prior to packing by placing them into chilled water at $12^{\circ} \mathrm{C}$ for 45 minutes. The lobsters were packed in plastic boxes lined with wet spons with varied densities of lobster (6 and 8 lobsters of 35-50 g in size/plastic box respectively). The plastic boxes were then packed in a larger stryrofoam box each containing 6 plastic boxes. Lobster were then transported in a vehicle from Jakarta to Lampung and returned to Jakarta at the $4^{\text {th }}$ day, followed by observation at the day $5^{\text {th }}, 6^{\text {th }}$ and $7^{\text {th }}$. Parameters observed were the survival rate by observing the mortality after the lobsters were refreshed for one day, and the weight loss. The results showed that the density affected the decrease of survival rates and weight loss of lobster during experiment. Packaging density of 6 lobsters/plastic box showed better survival rate than 8 lobsters/plastic box. Longer duration under transportation condition significantly decreased the survival rate and the lobster weight. Duration up to 7 days caused $10 \%$ weight loss, while transportation of lobster with density of 6 lobsters/plastic box for 6 days showed 97\% survival rate and the lobsters remained healthy after refreshed. Therefore, it is recommended not to keep the freshwater lobster for more than 6 days under transportation condition.

KEYWORDS: $\quad$ freshwater lobster, dry system transportation, density

\section{PENDAHULUAN}

Lobster air tawar (Cherax sp.) merupakan komoditi perikanan yang kini mulai banyak dibudidayakan. Salah satu jenis lobster air tawar yang paling banyak dibudidayakan adalah Cherax quadricarinatus atau red claw yang selama ini dipasarkan hidup untuk ikan hias. Meskipun demikian, jenis ini mempunyai tekstur daging dan rasa gurih yang melebihi lobster air laut (Jones, 2001). Peluang untuk memasarkan lobster air tawar jenis ini dalam keadaan hidup untuk konsumsi, baik untuk kebutuhan lokal maupun ekspor, sangat terbuka lebar, terutama ekspor ke Singapura, Hongkong, Jepang, Amerika, Uni Eropa, dan Timur Tengah (Anon., 2006b). Untuk memanfaatkan peluang

\footnotetext{
") Peneliti pada Balai Besar Riset Pengolahan Produk dan Bioteknologi Kelautan dan Perikanan, DKP
} 
tersebut diperlukan teknologi transportasi yang sesuai.

Untuk transportasi lobster air tawar hidup diperlukan teknologi transportasi yang dapat digunakan untuk kepentingan ekspor, yaitu dengan jarak tempuh yang jauh dan kapasitas tinggi yang mampu mempertahankan lobster tetap hidup sampai di negara tujuan dengan biaya angkut yang lebih murah. Pada transportasi dengan menerapkan suhu rendah dan lingkungan yang cukup lembab, lobster air tawar dapat bertahan hingga lebih dari 48 jam (Anon., 2007). Jika penanganan dan teknik transportasi yang diberikan tidak sesuai, maka dapat menyebabkan tingkat kematian lobster selama transportasi menjadi tinggi.

Agar derajat kelulusan hidup lobster tetap tinggi setelah sampai ke tempat tujuan, maka lobster harus dikondisikan dalam aktivitas dan metabolisme rendah. Semakin lama lobster bertahan hidup maka semakin luas jangkauan distribusinya. Pada dasarnya dalam transportasi ikan hidup, suhu rendah merupakan faktor yang sangat penting untuk menentukan tingkat kelulusan hidup selama transportasi (Berka, 1986). Beberapa penelitian untuk mempelajari penggunaan suhu rendah untuk transportasi lobster hidup telah dilakukan, diantaranya adalah kajian suhu rendah terhadap aktivitas dan metabolisme lobster hidup serta kajian metode imotilisasi lobster secara bertahap dan langsung. Selain itu, pengaruh pemberokan dan media untuk transportasi lobster air tawar yang merupakan faktor yang berpengaruh terhadap tingkat kelulusan hidup lobster juga telah dilakukan (Suryaningrum et al., 2006) .

Penelitian transportasi ikan hidup dengan sistem kering telah dilakukan terhadap lobster air laut dan udang windu tambak (Wibowo et al., 1994; Suparno et al., 1994). Hasil penelitian menunjukkan bahwa udang dapat ditransportasi hidup dengan sistem kering menggunakan media serbuk gergaji selama 24 jam, sedangkan lobster air laut dapat ditransportasi dengan media yang sama selama 35 jam dengan kelulusan hidup $100 \%$. Transportasi sistem kering untuk lobster air tawar yang telah dilakukan masyarakat selama ini adalah dengan mengangkut lobster dengan sistem curah dengan menggunakan keranjang yang dibasahi. Dengan cara ini lobster bertahan hidup kurang dari 24 jam. Cara lain adalah dengan menggunakan kotak plastik ukuran $25 \times 15 \times 6 \mathrm{~cm}$ yang dialasi dengan kertas koran dan setiap kotak plastik diisi dengan 6 ekor lobster. Dengan cara ini lobster air tawar dapat diangkut dari Yogyakarta ke Jakarta menggunakan kereta api berpendingin selama 24 jam dengan kelulusan hidup 80-88\% (Wibowo et al., 2005). Dari penelitian lain (Morrissy et al., 2001), lobster Cherax tenuimanus yang ditransportasikan dengan sistem kering dalam kotak stirofom yang diisi $5 \mathrm{~kg}$ lobster dengan menggunakan media sabut kelapa, mampu bertahan hingga 72 jam dengan kelulusan hidup $100 \%$. Sementara itu, lobster air tawar tahan terhadap kelarutan oksigen yang sangat rendah, bahkan dalam waktu lama (Lawrence, 2001). Lobster air tawar juga tahan terhadap salinitas air sampai 8 per mill serta kisaran suhu lingkungan yang cukup besar, yaitu 9$36^{\circ} \mathrm{C}$ (Jones, 2001).

Penelitan ini dilakukan dengan tujuan mempelajari kemampuan lobster air tawar untuk bertahan hidup selama transportasi menggunakan sistem kering dengan berbagai tingkat kepadatan. Hasilnya diharapkan dapat memberikan informasi tentang teknologi transportasi hidup yang efisien dan ekonomis yang dapat menghasilkan tingkat kelulusan hidup lobster yang tinggi dengan waktu transportasi yang lama.

\section{BAHAN DAN METODE}

\section{Bahan dan Alat}

Bahan utama yang digunakan dalam penelitian ini adalah lobster air tawar jenis capit merah atau red claw (Cherax quadricarinatus) dalam keadaan hidup yang diperoleh dari hasil budidaya di Yogyakarta. Lobster yang digunakan berukuran komersial 25 ekor/ $\mathrm{kg}$ (35-50 gram/ekor), panjang total $16-22 \mathrm{~cm}$, panjang karapak 9-14 cm dan lebar 1,9-2,6 cm. Lobster dipilih yang utuh, tidak moulting, kondisinya sehat dan bugar.

Bahan bantu lain yang digunakan dalam penelitian ini adalah es air tawar untuk mendinginkan media air, kotak plastik berukuran $25 \times 15 \times 6 \mathrm{~cm}$, spons dengan ketebalan $50 \mathrm{~mm}$ sebagai alas pada kotak plastik, kotak styrofoam berukuran $60 \times 40 \times 40 \mathrm{~cm}$, lak ban, kertas koran, dan es dalam kantong plastik $( \pm 400$ g/kantong).

Alat yang digunakan dalam penelitian ini adalah bak plastik ukuran $40 \times 60 \times 30 \mathrm{~cm}$, sirkulator air, DO meter YSI, dan termometer (thermorecorder Kan May) untuk mengamati perubahan suhu ruang pengemas selama penyimpanan. Sedangkan alat bantu lainnya adalah timbangan, ember plastik, penggaris, serok untuk mengambil contoh, dan kantong plastik.

\section{Metode Penelitian}

Perlakuan yang digunakan dalam penelitian ini adalah kepadatan (6 dan 8 ekor/kotak) dan durasi dalam kondisi transportasi (5, 6 , dan 7 hari). Sebelum dikemas, lobster dipingsankan secara langsung dengan cara memasukkannya ke dalam air pada suhu $\pm 12^{\circ} \mathrm{C}$ dan dipertahankan pada suhu tersebut selama 45 menit (Ikasari et al., 2008). Selama pemingsanan, 
dilakukan pengamatan terhadap perubahan aktivitas lobster dan kualitas air yang digunakan sebagai media pemingsanan. Setelah waktu pemingsanan tercapai, lobster dikemas dalam kotak plastik yang dasarnya diberi spons yang telah direndam air dingin $\left(12^{\circ} \mathrm{C}\right)$ selama 30 menit (Hastarini et al., 2006).

Sebagai kontrol digunakan sistem kemasan yang biasa dilakukan oleh pedagang lobster, yaitu lobster langsung dikemas tanpa perlakuan shock dengan kepadatan 6 ekor/kotak plastik (Wibowo et al., 2005). Lobster yang telah dipingsankan dimasukkan ke dalam kotak plastik dengan kepadatan 6 dan 8 ekor setiap kotak plastik. Kotak plastik yang telah berisi lobster tersebut kemudian dimasukkan ke dalam kotak styrofoam sebanyak 6 kotak plastik per styrofoam. Untuk mempertahankan agar suhu ruang pengemas tetap dingin, pada dasar kotak styrofoam dan di atas tumpukan kotak plastik ditambahkan 3 bungkus es (masing-masing $400 \mathrm{~g}$ dibungkus kantong plastik dan kertas koran) yang diletakkan secara diagonal. Kotak styrofoam ditutup dengan penutupnya yang sebelumnya telah dipasang probe thermorecorder untuk mencatat perubahan suhu ruang pengemas selama kondisi transportasi dan direkatkan dengan menggunakan lak ban. Selama kondisi transportasi, dilakukan pengamatan perubahan suhu ruang pengemas setiap 30 menit sekali.
Uji transportasi dilakukan dengan mengangkut lobster dari Jakarta - ke Lampung pergi-pulang. Berangkat dari Jakarta pada sore hari, dan sampai di Lampung kemasan dibiarkan pada suhu kamar selama 3 hari dan pada hari ke-4 diangkut kembali ke Jakarta pada sore hari. Setelah 5, 6, dan 7 hari, kemasan dibongkar dan lobster ditimbang untuk mengetahui susut bobot selama dalam kondisi transportasi. Lobster yang masih hidup ditempatkan di tempat terbuka untuk di angin-anginkan selama 30 menit, agar gas amonia dan $\mathrm{H}_{2} \mathrm{~S}$ menguap. Kemudian lobster dibugarkan kembali dalam air tanpa aerasi, tetapi ketinggian air tidak sampai merendam badan lobster. Setelah dibugarkan selama 1 jam, lobster ditampung dalam bak penampung agar aktivitas metabolisme lobster normal kembali. Setelah dibugarkan selama 24 jam, mortalitas lobster dihitung dan dilakukan pengamatan terhadap metabolit di dalam air pembugaran.

\section{HASIL DAN BAHASAN}

\section{Aktivitas Lobster Selama Shock}

Hasil pengamatan aktifitas lobster saat shock pada suhu $12^{\circ} \mathrm{C}$ selama 45 menit dapat dilihat pada Tabel 1. Perubahan aktivitas lobster yang mencolok terjadi pada saat lobster di-shock langsung pada suhu

Tabel 1. Aktivitas lobster yang mendapat perlakuan shok langsung pada suhu $12^{\circ} \mathrm{C}$ selama 45 menit Table 1. Activity of freshwater lobster after shocked directly at $12^{\circ} \mathrm{C}$ for 45 minutes

\begin{tabular}{|c|c|c|c|}
\hline No & $\begin{array}{l}\text { Waktul } \\
\text { Time } \\
\text { (min) }\end{array}$ & $\begin{array}{l}\text { Suhul } \\
\text { Temperature } \\
\left({ }^{\circ} \mathrm{C}\right)\end{array}$ & Aktivitas lobster/Activity of lobster \\
\hline 1 & 0 & $11.3-11.5$ & $\begin{array}{l}\text { Ketika lobster dimasukkan pada media air dingin }\left(12^{\circ} \mathrm{C}\right) \text {, sebagian lobster } \\
\text { langsung menyentak-nyentak kemudian jatuh dengan posisi tubuh miring. } \\
\text { Lobster tidak bergerak, respon lemah, dan sebagian lobster limbung/When put } \\
\text { into the cooled water }\left(12^{\circ} \mathrm{C}\right) \text {, some of the lobsters struggled and fell down. } \\
\text { Lobster's respond was weaker and some of the lobsters lost their balance. }\end{array}$ \\
\hline 2 & 15 & $11.5-12.1$ & $\begin{array}{l}\text { Lobster yang rebah tegak kembali, ekor terlipat ke depan, diam, respon terhadap } \\
\text { rangsangan fisik lemah, kaki jalan bergerak lemah dan keseimbangan } \\
\text { hilang/Laying lobsters rose, tail was folded to the front side, respond to the } \\
\text { physical stimulation was weak, walking legs moved weakly and lobsters lost } \\
\text { their balance. }\end{array}$ \\
\hline 3 & 30 & $11.1-12.4$ & $\begin{array}{l}\text { Lobster tidak bergerak, keseimbangan hilang, ketika diangkat tenang, kaki jalan } \\
\text { diam dan kaku/Lobsters didn't move, lost their balance, no movement when lift } \\
\text { from water, no movement of the walking legs and became stiff. }\end{array}$ \\
\hline 4 & 45 & $11.3-12.5$ & $\begin{array}{l}\text { Lobster tidak bergerak, posisi tubuh sebagian miring, keseimbangan hilang, } \\
\text { ketika disentuh diam, kaki renang dan kaki jalan kaku/Lobsters didn't move, and } \\
\text { laid on one side, lost their balance, no respond upon physical tap; swimming } \\
\text { and walking legs were stiff. }\end{array}$ \\
\hline
\end{tabular}

Keterangan/Note: Media air, $\mathrm{pH}: 7-7,4 ; \mathrm{O}_{2}$ terlarut: 7,6-8,6 mg/l /

Water Media, $\mathrm{pH}$ : 7-7.4; Dissolved $\mathrm{O}_{2}(\mathrm{DO}):$ 7.6-8.6 mg/l 
$12^{\circ} \mathrm{C}$, yaitu gerakan lobster yang menyentak-nyentak sebagai respon atas perubahan suhu media yang tibatiba dari suhu kamar (suhu $28,2^{\circ} \mathrm{C}$ ) ke suhu $12^{\circ} \mathrm{C}$. Respon tersebut terlihat dari gerakan reflek penolakan dengan meloncat-loncat tidak terkendali, berenang dengan arah yang tidak jelas. Perubahan suhu yang cukup drastis menyebabkan lobster shock terhadap lingkungan yang tidak sesuai dengan kenyamanan hidupnya. Namun gerakan panik tersebut hanya berlangsung kurang dari 3 menit kemudian lobster diam. Respon tersebut juga terjadi jika suhu media diturunkan secara bertahap dan mencapai suhu 14$15^{\circ} \mathrm{C}$, lobster akan memasuki fase panik dan menunjukkan respon menyentak-nyentak. Pada fase ini respirasi akan meningkat dengan tajam kemudian turun sampai mencapai respirasi terendah.

Tingkat respirasi yang cukup rendah tersebut menyebabkan lobster terganggu keseimbangannya sehingga lobster tidak dapat menyangga tubuhnya sendiri dan jatuh dengan posisi tubuh miring. Kondisi aktivitas lobster ini sama dengan kondisi lobster yang suhu medianya diturunkan secara bertahap $\left(0,4^{\circ} \mathrm{C} / 5\right.$ menit) sampai suhu $12^{\circ} \mathrm{C}$ (Wibowo et al., 2005). Setelah 5 menit berada pada suhu $12^{\circ} \mathrm{C}$ lobster diam, kaki jalan maupun kaki renang tidak bergerak. Ketika disentuh dan diangkat, lobster diam dan melayanglayang ketika dimasukkan kembali ke dalam air. Kondisi ini menunjukkan bahwa lobster telah hilang keseimbangannya. Keadaan ini tidak berubah sampai waktu shock selama 45 menit selesai. Pada saat diangkat, semua lobster diam, sebagian masih menunjukkan adanya gerakan kejut cukup lemah. Ketika dikemas dalam kotak plastik, lobster tenang, tidak meronta, namun beberapa menit kemudian kaki jalan dan kaki renang bergerak-gerak. Hal ini menunjukkan bahwa toleransi lobster terhadap perubahan suhu sangat baik sebagaimana dinyatakan oleh Jones (2001) bahwa kisaran suhu untuk hidup lobster air tawar sangat luas, yaitu dari $10-36^{\circ} \mathrm{C}$.

\section{Kelulusan Hidup Lobster Air Tawar Setelah Transportasi}

Kelulusan hidup dihitung setelah lobster dibugarkan kembali selama 1 jam untuk melihat kemampuan lobster beradaptasi kembali dalam media air. Uji ketahanan lobster yang dibiarkan dalam kondisi transportasi selama 5, 6, dan 7 hari dengan tingkat kepadatan yang berbeda menghasilkan mortalitas dan tingkat kebugaran lobster yang berbeda pula. Hubungan antara tingkat kelulusan hidup lobster dan lamanya dalam kondisi transportasi untuk masing-masing tingkat kepadatan yang diuji dapat dilihat pada Gambar 1.

Terlihat pada Gambar 1 bahwa kepadatan berpengaruh terhadap turunnya kelulusan hidup lobster. Lobster yang dikemas dengan kepadatan 6 ekor/kotak plastik dengan waktu transportasi 6 hari menghasilkan tingkat kelulusan hidup yang lebih tinggi dibandingkan dengan kepadatan 8 ekor/kotak plastik

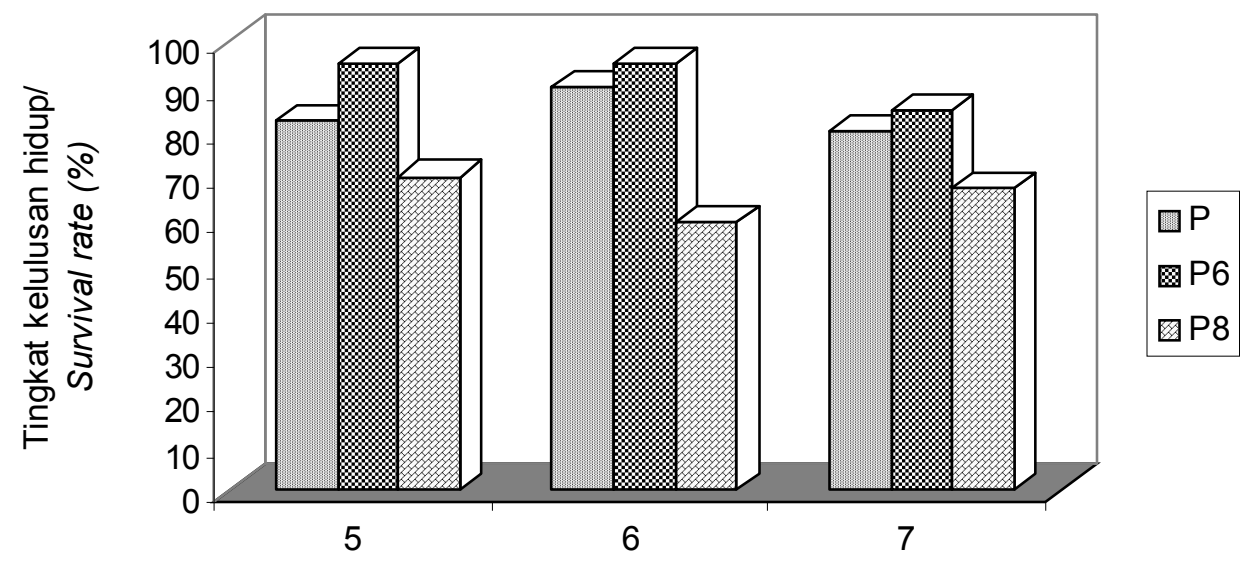

Durasi dalam kondisi transportasi (hari)/ Duration under transportation condition (days)

Keterangan/Note: $\mathrm{P}=$ Pembanding/Reference

P6 = Kepadatan 6 lobster/kotak plastik / Density 6 lobsters/plastic box

P8 = Kepadatan 8 lobster/kotak plastik / Density 8 lobsters/plastic box

Gambar 1. Hubungan antara tingkat kelulusan hidup lobster dengan durasi dalam kondisi transportasi pada tingkat kepadatan yang berbeda.

Figure 1. Relationship between lobster's survival rate and duration under transportation condition at different densities. 
dan kelompok pembanding. Kelompok pembanding merupakan kelompok lobster yang ditransportasikan dengan cara yang digunakan masyarakat dengan kepadatan 6 ekor/kotak plastik, tetapi tanpa perlakuan shock, menggunakan media spons. Tingginya tingkat kematian pada perlakuan dengan kepadatan 8 ekor/kotak plastik disebabkan terbatasnya oksigen untuk respirasi di dalam kotak plastik.

Tingginya tingkat kematian juga disebabkan adanya efek domino, yaitu apabila dalam kemasan plastik tersebut ada lobster yang mati pada awal penyimpanan, maka kematian tersebut menyebabkan kematian lobster yang lainnya. Lobster yang mati akan mengalami proses pembusukan yang menyebabkan terbentuknya gas-gas seperti amonia, dan $\mathrm{H}_{2} \mathrm{~S}$ yang bersifat toksik. Menurut Bartelme (2006) adanya gas tersebut menyebabkan rusaknya jaringan insang, yang terlihat dari perubahan warna insang menjadi hitam sehingga respirasi lobster terganggu, dan menyebabkan kematian. Hal ini dapat dilihat apabila dalam satu kemasan plastik ada lobster yang mati kemudian mengalami pembusukan maka jumlah lobster yang mati dalam kemasan tersebut cukup banyak. Sebaliknya, jika dalam kemasan tidak ada lobster yang mati atau lobster yang mati tidak membusuk, maka semua atau sebagian besar lobster dalam kotak plastik tersebut hidup dan kematian salah satu lobster tidak berakibat pada kematian lobster lainnya.

Pada lobster yang dikemas dengan kepadatan 6 ekor maupun 8 ekor/kotak plastik, kelulusan hidupnya selama berada dalam kondisi transportasi berfluktuasi. Lobster yang didiamkan selama 5 hari justru menghasilkan kelulusan hidup yang lebih rendah dibandingkan dengan lobster yang didiamkan selama 6 hari. Kematian lobster yang didiamkan 5 hari dipengaruhi oleh beberapa faktor antara lain kualitas kesehatan lobster yang kurang baik dibandingkan dengan lobster yang didiamkan 6 hari. Pada lobster yang didiamkan 5 hari terdapat beberapa di antaranya mati pada awal penyimpanan yang kemungkinan disebabkan oleh kualitas kesehatannya kurang baik dan menyebabkan efek domino pada kematian lobster lainnya. Dalam transportasi lobster hidup kualitas kesehatan dan kebugaran merupakan faktor penting yang menghasilkan kelulusan hidup yang tinggi. Dari hasil percobaan terlihat bahwa semakin lama durasi dalam kondisi transportasi semakin menurun kelulusan hidupnya dan penurunan tersebut dipengaruhi oleh kepadatan lobster.

Menurut Ayres \& Wood (1977), salah satu syarat yang sangat menentukan keberhasilan transportasi lobster hidup adalah kondisi kesehatan dan kebugaran lobster sebelum ditransportasikan. Sedangkan Praseno (1990) menyatakan dalam transportasi ikan hidup kualitas ikan yang diangkut merupakan kriteria yang sangat menentukan dalam keberhasilan proses transportasi. Ikan harus dalam kondisi sehat dan baik dan disarankan untuk mengeliminasi ikan yang lemah. Sedangkan menurut Jeffs (2003) kelulusan hidup lobster dipengaruhi oleh ukuran lobster yang akan ditranspor. Lobster yang berukuran kecil memiliki tingkat kematian yang lebih tinggi bila dibandingkan dengan lobster yang berukuran besar. Hal ini didukung oleh hasil penelitian Romero \& Murillo (1997) dan Morrissy et al. (2001), transportasi bibit lobster air tawar (ukuran $10 \mathrm{~g}$ ) dengan menggunakan sistem basah selama 24 dan 48 jam, menghasilkan kelulusan hidup sebesar 88,7 dan $72,7 \%$. Sedangkan lobster dengan ukuran komersial 30-50 g yang transportasikan dengan sistem kering mampu bertahan selama 72 jam dengan kelulusan hidup $100 \%$.

Ketahanan hidup lobster air tawar pada media yang lembab di luar air lebih baik bila dibandingkan dengan lobster laut jenis hijau pasir (Panilurus humarus) yang ditransportasikan dengan sistem kering dengan menggunakan media serbuk gergaji. Lobster hijau pasir hanya mampu bertahan selama 35 jam dengan kelulusan hidup hidup $100 \%$ atau 40 jam dengan kelulusan hidup hidup $87,5 \%$. Sedangkan hasil penelitian Vijayakumaran \& Radhaskrishnan (1997) terhadap lobster hijau yang ditranspor hidup selama 3 hari rata-rata kelulusan hidupnya sebesar $93,5 \%$.

Pada penelitian ini lobster air tawar mampu bertahan dalam kondisi transportasi selama 7 hari (168 jam) apabila ditransportasi dengan kepadatan 6 ekor/ kotak plastik dengan rata-rata kelulusan hidup $95 \%$. Pada kondisi transportasi lebih dari 7 hari kemungkinan masih menghasilkan tingkat kelulusan hidup yang tinggi, mengingat setelah dibugarkan kembali aktivitas lobster masih normal kembali. Transportasi yang terlalu lama menyebabkan kematian lobster setelah pembugaran kembali karena lobster tidak makan dalam waktu lama. Hal ini terlihat pada lobster yang diberok selama 3 hari, kemudian disimpan dalam kemasan kering selama 6 hari, setelah pembugaran lobster tidak mau makan dan akhirnya mati (Suryaningrum et al., 2006). Bertahannya lobster di luar media air yang cukup lama ini di antaranya disebabkan karena spon yang digunakan sebagai alas untuk media transportasi lobster cukup lembab. Jumlah air yang terdapat dalam media spon tersebut sebenarnya cukup tinggi, karena spon dapat menyerap air sebanyak 14 kali dari berat sponnya sendiri (Hastarini, 2006). Kondisi yang cukup basah tersebut menyebabkan lobster mampu bertahan dalam kurun waktu yang cukup lama. 
Dari pengamatan yang dilakukan, lobster yang dikemas dengan kepadatan 6 ekor/kotak plastik saat dibongkar pada hari ke 5, lobster langsung bergerak aktif. Ketika diangkat, lobster meronta-ronta dengan gerakan lemah. Warna cangkang lobster pada kelompok ini tampak tetap hitam kebiru-biruan. Sedangkan warna cangkang lobster pada kelompok yang dikemas dengan kepadatan 8 ekor/kotak plastik dan kelompok pembanding telah berubah menjadi agak kemerahan. Dalam penelitian ini, warna lobster yang dikemas dengan kepadatan 8 ekor/kotak plastik menjadi kemerahan yang mungkin disebabkan oleh terbentuknya gas $\mathrm{H}_{2} \mathrm{~S}$ dari lobster yang mati. Pada dasarnya pigmen merah pada karapas merupakan komponen yang paling stabil pada saat lobster masih hidup. Stabilitas warna tersebut dipengaruhi oleh suhu, asam, atau basa yang menyebabkan terjadinya perubahan warna menjadi agak kemerahan (Anon., 2006a).

Pada pembongkaran hari ke-6, pada kemasan dengan kepadatan 6 ekor/kotak plastik, lobster langsung bergerak aktif ketika kemasan dibuka. Sedangkan pada kemasan dengan kepadatan 8 ekor/ kotak plastik, lobster baru bergerak aktif setelah 1-2 menit setelah dikeluarkan dari kemasan. Lambannya aktivitas setelah kemasan dibuka mungkin disebabkan oleh timbulnya gas amonia dan $\mathrm{H}_{2} \mathrm{~S}$ yang dihasilkan dari lobster yang mati. Hal yang sama juga terjadi pada lobster yang dibongkar pada hari ke-7, dengan kepadatan 6 ekor/kotak plastik. Ketika kemasan dibuka, lobster langsung bergerak aktif dan bergerombol di salah satu sudut ketika dimasukkan ke dalam ember tanpa air. Sedangkan pada kemasan dengan kepadatan 8 ekor/kotak plastik ketika dibuka lobster cenderung diam dan setelah 2-3 menit baru aktif kembali.

\section{Pola Perubahan Suhu Ruang Pengemas Selama Transportasi Lobster Hidup}

Hasil pengamatan suhu ruang pengemas selama kondisi transportasi dapat dilihat pada Gambar 2. Selama kondisi transportasi, suhu media meningkat setelah 1 hari penyimpanan. Pada awal penyimpanan sampai 6 jam pertama, suhu media masih berada di bawah $20^{\circ} \mathrm{C}$, namun setelah 1 hari penyimpanan suhu kemasan naik secara perlahan, bahkan mencapai $32,9^{\circ} \mathrm{C}$ pada jam ke 28,5 . Pola suhu ruang pengemas berkisar antara $28-30,4^{\circ} \mathrm{C}$. Suhu di atas $30^{\circ} \mathrm{C}$ merupakan suhu kritis yang tidak dapat ditoleransi dalam transportasi ikan hidup. Akan tetapi kondisi tersebut dapat ditoleransi oleh lobster air tawar yang membuktikan bahwa lobster air tawar memiliki karakter tidak mudah stress (Anon., 2006a). Lobster air tawar jenis red claw mempunyai kisaran suhu untuk dapat bertahan hidup yang cukup besar yaitu berkisar antara $10-36^{\circ} \mathrm{C}$ dengan suhu optimum untuk hidupnya adalah $23-31^{\circ} \mathrm{C}$ (Jones, 2001). Dibandingkan dengan udang yang sangat rentan terhadap perubahan suhu, lobster air tawar lebih tahan terhadap perubahan suhu. Hasil penelitian Goodrick et al. (1993) terhadap Paneus japonicus yang ditransportasi dengan suhu 22 dan $17^{\circ} \mathrm{C}$, kelulusan hidupnya berturut-turut adalah 20 dan $80 \%$ setelah ditranspor selama 32 jam. Lebih

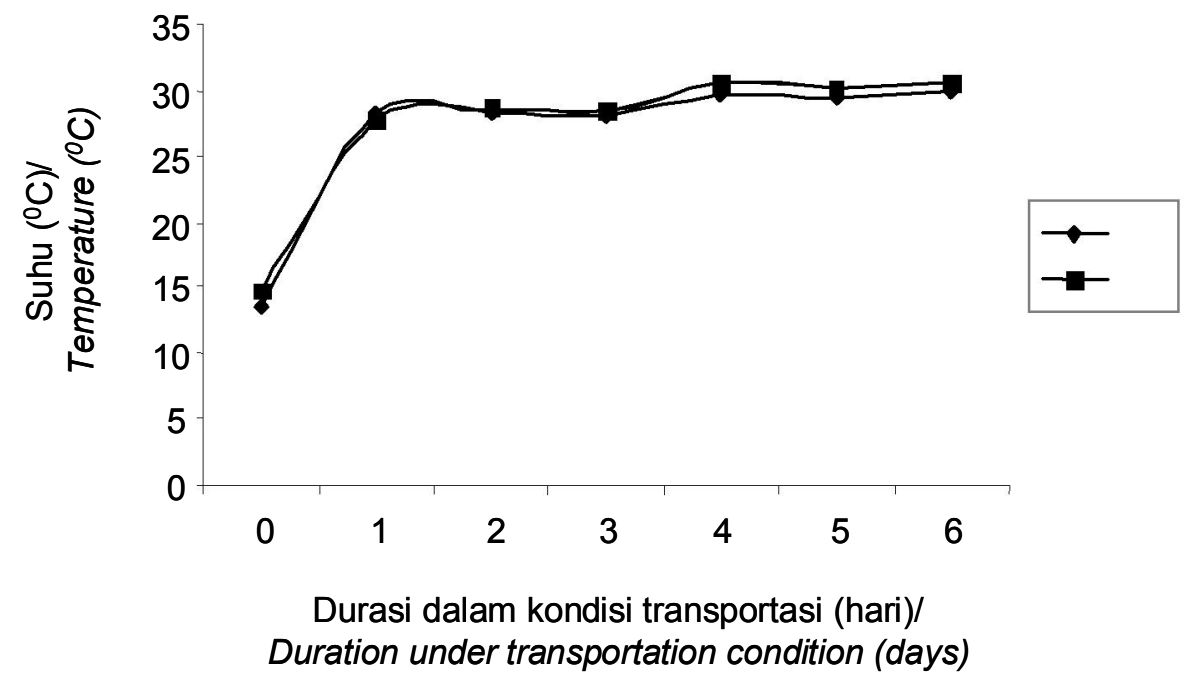

Keterangan/Note: P6 = Kepadatan 6 lobster/kotak plastik / Density 6 lobsters/plastic box P8 = Kepadatan 8 lobster/kotak plastik / Density 8 lobsters/plastic box

Gambar 2. Profil suhu ruang pengemas lobster selama penundaan dalam kondisi transportasi.

Figure 2. Temperature profile of freshwater lobster packaging boxes during delay under transportation condition. 
lanjut dikatakan bahwa suhu optimum untuk transportasi udang adalah $12-15^{\circ} \mathrm{C}$ pada musim panas dan $10-13^{\circ} \mathrm{C}$ pada musim dingin.

Kematian lobster yang dikemas dengan kepadatan 8 ekor/kotak plastik diduga terjadi pada saat suhu kemasan berada di atas $30^{\circ} \mathrm{C}$. Kepadatan yang tinggi dan suhu media kemasan yang tinggi menyebabkan lobster tidak mampu bertahan hidup di luar air.

Suhu ruang pengemas memegang peranan penting dalam menentukan tingkat kelulusan hidup lobster. Suhu ruang pengemas yang terlalu rendah atau terlalu tinggi akan menyebabkan mortalitas yang tinggi selama transportasi. Penambahan es dengan jumlah, berat dan posisi yang didasarkan dari hasil penelitian sebelumnya pada waktu tertentu mampu mempertahankan suhu kemasan berkisar antara 13,6$20,6^{\circ} \mathrm{C}$ (Suryaningrum et al., 2006). Penambahan es yang terlalu banyak akan menyebabkan suhu ruang pengemas turun sampai di bawah $10^{\circ} \mathrm{C}$ yang mengakibatkan sebagian besar lobster mengalami hypothermal yang berakhir pada kematian lobster.

\section{Kondisi Lobster Setelah Pembugaran}

Hasil pengamatan selama pembugaran lobster yang telah berada dalam kondisi transportasi selama 5 hari, dan dikemas dengan kepadatan 6 ekor/kotak plastik, menunjukkan bahwa saat dimasukkan dalam air, lobster langsung bergerak dan berjalan-jalan, respon sangat cepat menyentak-nyentak ketika disentuh. Aktivitas lobster normal kembali setelah berada di dalam air selama 1 jam. Adapun sebagian lobster yang dikemas dengan kepadatan 8 ekor/kotak plastik meskipun sudah dibugarkan selama 1 jam aktivitas dan respon terhadap rangsangan masih lemah. Setelah lobster ditampung selama 1 jam air berubah menjadi kotor dan berwarna kecoklatan. Hal ini disebabkan karena banyaknya kotoran yang dikeluarkan oleh lobster. Sedangkan pada lobster pembanding, sebagian kecil lemah dan sebagian besar aktivitasnya normal kembali.

Pengamatan visual terhadap air yang digunakan sebagai media pembugaran untuk lobster yang dikemas dengan kepadatan 8 ekor/kotak plastik, dan dibiarkan dalam kondisi transportasi selama 6 dan 7 hari, menunjukkan bahwa air agak keruh dan berwarna agak kecoklatan. Tingkat kebugaran lobster dengan kepadatan 8 ekor/kotak plastik juga lebih rendah dibandingkan dengan lobster yang dikemas dengan kepadatan 6 ekor/kotak plastik. Hal ini ditunjukkan dengan respon yang kurang sensitif terhadap rangsangan yang diberikan.

Pengamatan terhadap mutu air setelah pembugaran dapat dilihat pada Gambar 3, 4, dan 5. Hasil pengamatan terhadap kadar $\mathrm{CO}_{2}$ lobster setelah dibugarkan selama 1 jam dapat dilihat pada Gambar 3. Rata-rata kadar $\mathrm{CO}_{2}$ yang diekskresikan lobster setelah dibugarkan kembali berkisar antara 0,44-1,76 $\mathrm{mg} / \mathrm{l}$, semakin lama waktu penundaan dalam kondisi

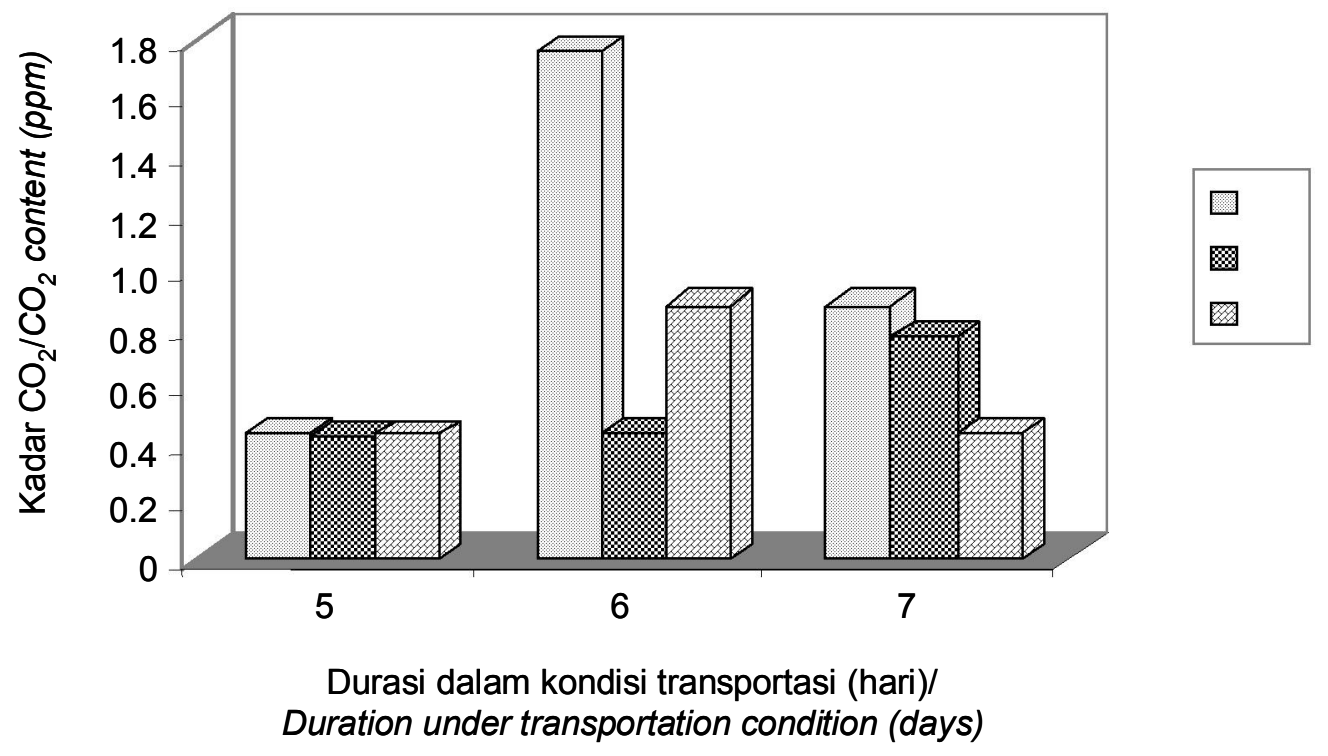

Keterangan/Note: $\mathrm{P}=$ Pembanding/Reference

P6 = Kepadatan 6 lobster/kotak plastik / Density 6 lobsters/plastic box

P8 = Kepadatan 8 lobster/kotak plastik / Density 8 lobsters/plastic box

Gambar 3. Kandungan $\mathrm{CO}_{2}$ di dalam air pembugaran setelah pembugaran lobster selama 1 hari.

Figure 3. $\mathrm{CO}_{2}$ content in the refreshment water after lobster refreshed for 1 day. 


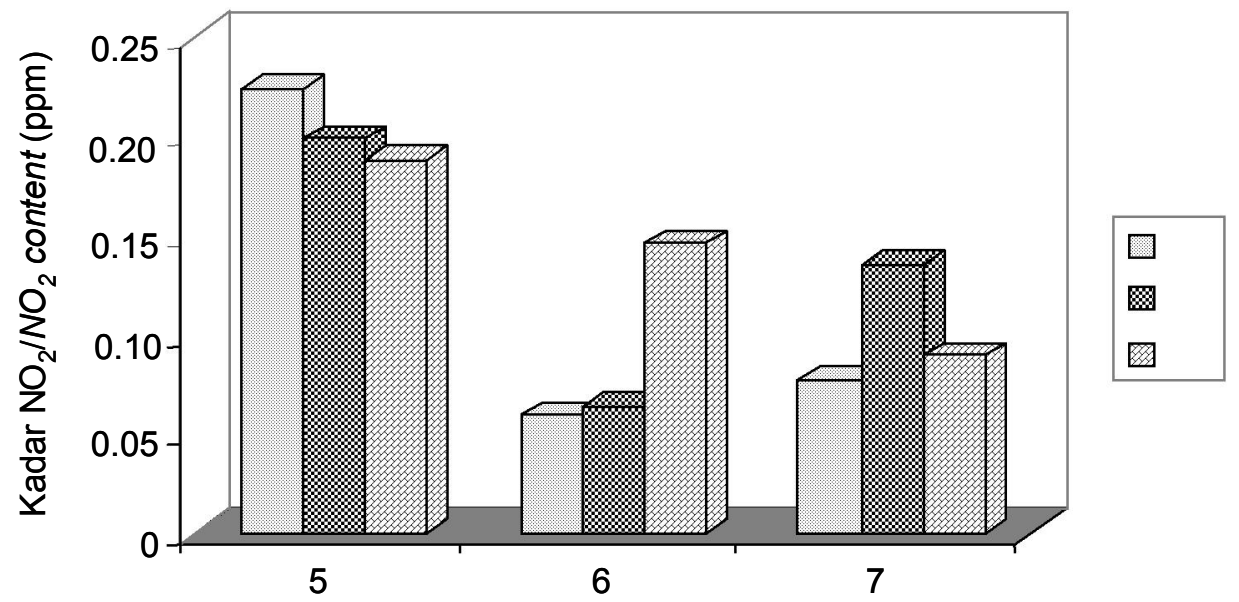

Durasi dalam kondisi transportasi (hari)/ Duration under transportation condition (days)

Keterangan/Note: $\mathrm{P}=$ Pembanding/Reference

P6 = Kepadatan 6 lobster/kotak plastik / Density 6 lobsters/plastic box

P8 = Kepadatan 8 lobster/kotak plastik / Density 8 lobsters/plastic box

Gambar 4. Kandungan $\mathrm{NO}_{2}$ di dalam air pembugaran setelah pembugaran lobster selama 1 hari. Figure 4. $\mathrm{NO}_{2}$ content in the refreshment water after lobster refreshed for 1 day.

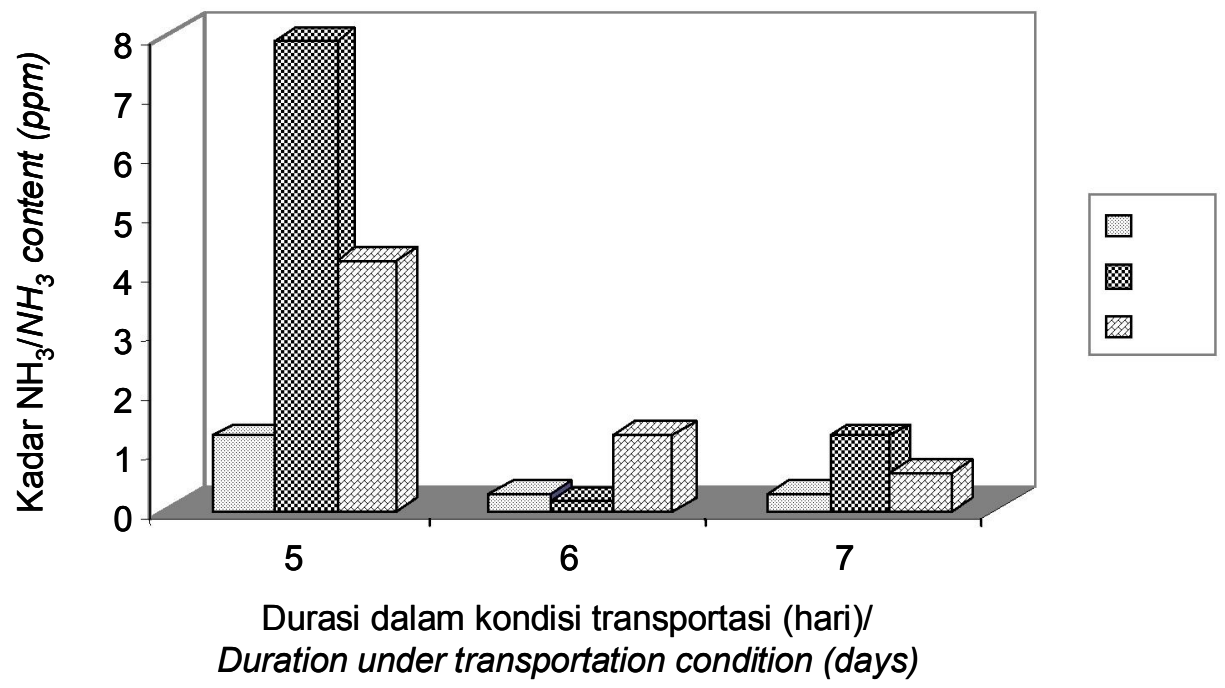

\footnotetext{
Keterangan/Note: $\mathrm{P}=$ Pembanding/Reference

P6 = Kepadatan 6 lobster/kotak plastik / Density 6 lobsters/plastic box

P8 = Kepadatan 8 lobster/kotak plastik / Density 8 lobsters/plastic box
}

Gambar 5. Kandungan $\mathrm{NH}_{3}$ di dalam air pembugaran setelah pembugaran lobster selama 1 hari.

Figure 5. $\mathrm{NH}_{3}$ content in the refreshment water after lobster refreshed for 1 day.

transportasi semakin tinggi ekskresi $\mathrm{CO}_{2}$ yang dihasilkan. Lobster yang dikemas dengan kepadatan 8 ekor/kotak plastik menghasilkan ekskresi $\mathrm{CO}_{2}$ lebih tinggi dibandingkan dengan yang dikemas dengan kepadatan 6 ekor/kotak plastik, namun ekskresi tertinggi dihasilkan oleh lobster yang digunakan sebagai pembanding. $\mathrm{CO}_{2}$ dihasilkan sebagai oksidasi senyawa organik yang berasal dari makanan selama proses respirasi.
Menurut Itazawa (1990), jika dalam proses respirasi jumlah oksigen berkurang maka akan terjadi peningkatan jumlah $\mathrm{CO}_{2}$ di dalam proses metabolismenya. Oleh karena itu, semakin lama waktu transportasi semakin tinggi $\mathrm{CO}_{2}$ yang dihasilkan. Sedangkan hasil buangan metabolit yang berupa nitrit dan amonia setelah lobster dibugarkan selama 1 hari menunjukkan bahwa semakin lama dalam kondisi transportasi semakin kecil metabolit 
nitrit dan amonia yang dihasilkan seperti terlihat pada Gambar 4 dan 5. Adapun tingkat kepadatan yang berbeda menghasilkan jumlah metabolit nitrit dan amonia yang hampir sama.

\section{Mortalitas Lobster Setelah Pembugaran}

Mortalitas lobster setelah pembugaran menunjukkan bahwa semakin lama durasi dalam kondisi transportasi, semakin besar tingkat mortalitas lobster setelah dibugarkan 1 hari, seperti yang terlihat pada Tabel 2. Kematian terbanyak lobster terjadi pada lobster setelah didiamkan dalam kondisi transportasi selama 7 hari. Waktu transportasi yang semakin lama dapat menyebabkan rusaknya insang, yang menurut Morrissy et al. (2001) insang tidak reversible setelah ditransportasi dalam keadaan kering.

\section{Penurunan Bobot Lobster Selama dalam Kondisi Transportasi}

Penurunan bobot lobster selama dalam kondisi transportasi dihitung berdasarkan selisih bobot awal sebelum dan sesudah percobaan. Penurunan bobot lobster selama dalam kondisi transportasi dapat dilihat pada Gambar 6. Semakin lama durasi dalam kondisi transportasi semakin susut bobot lobster. Penurunan bobot lobster berkisar antara 3,45-10\% dari berat awal. Hasil penelitian Morrissy et al. (2001) terhadap Cherax tenuimanus, bobot lobster setelah ditransportasikan selama 24 jam turun sebesar $3,9 \%$ dan setelah 48 jam menjadi $4,3 \%$. Idealnya dalam pemasaran lobster penurunan bobot tidak boleh lebih dari $5 \%$ agar tidak rugi. Penurunan bobot yang tinggi dalam penelitian ini disebabkan durasi dalam kondisi

Tabel 2. Mortalitas lobster setelah pembugaran 1 hari (\%)

Table 2. Mortality of freshwater lobster after 1 day refreshment (\%)

\begin{tabular}{lccc}
\hline \multirow{1}{*}{ Perlakuan/Treatment } & \multicolumn{3}{c}{$\begin{array}{c}\text { Durasi dalam kondisi transportasi/ } \\
\text { Duration under transportation condition }\end{array}$} \\
\cline { 2 - 4 } & $\mathbf{5}$ hari/5 days & $\mathbf{6}$ hari/6 days & $\mathbf{7}$ hari/7 days \\
\hline $\begin{array}{l}\text { Pembanding/Reference } \\
\text { Kepadatan 6 lobster/kotak plastik/ }\end{array}$ & $3.3 \pm 0$ & 0 & $6.6 \pm 0$ \\
$\begin{array}{l}\text { Density 6 lobsters/plastic box } \\
\text { Kepadatan 8 lobster/kotak plastik/ } \\
\text { Density 8 lobsters/plastic box }\end{array}$ & 0 & 0 & $4.9 \pm 0.5$ \\
\hline
\end{tabular}

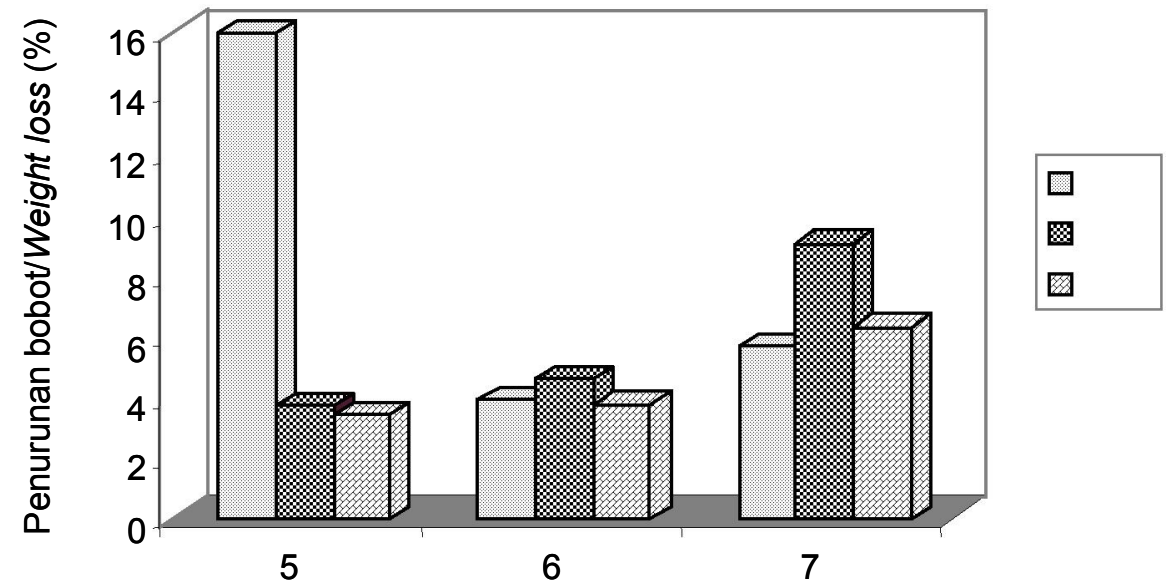

Durasi dalam kondisi transportasi (hari)/ Duration under transportation condition (days)

Keterangan/Note: $\mathrm{P}=$ Pembanding/Reference

P6 = Kepadatan 6 lobster/kotak plastik / Density 6 lobsters/plastic box

P8 = Kepadatan 8 lobster/kotak plastik / Density 8 lobsters/plastic box

Gambar 6. Penurunan bobot lobster selama dalam kondisi transportasi.

Figure 6. Weight loss of freshwater lobster during delay under transportation condition. 
transportasi lebih dari 5 hari, sedangkan lobster biasanya ditransportasikan untuk tujuan ekspor paling lama 72 jam (3 hari).

Pada lobster yang dikemas dengan kepadatan 6 ekor/kotak plastik, penurunan bobotnya lebih banyak dibandingkan dengan lobster yang dikemas dengan kepadatan 8 ekor/kotak plastik. Hal ini diduga lobster yang dikemas dengan kepadatan 8 ekor/kotak plastik terlalu padat, sehingga mengurangi aktivitas lobster selama dalam kondisi transportasi. Kondisi ini menyebabkan lobster yang dikemas dengan kepadatan 8 ekor/kotak plastik mengalami penurunan bobot lebih kecil dibandingkan dengan lobster yang dikemas dengan kepadatan 6 ekor/kotak plastik. Di samping itu, lobster yang dikemas dengan kepadatan 8 ekor/kotak plastik banyak yang mati, sedangkan lobster mati tidak mengalami penurunan bobot. Jika dibandingkan dengan pembanding, lobster yang tidak diberi perlakuan pemingsanan pada suhu dingin penurunan bobotnya lebih tinggi dibandingkan dengan lobster yang diberi perlakuan pemingsanan.

\section{KESIMPULAN}

Dari hasil penelitian ini dapat disimpulkan bahwa kepadatan berpengaruh terhadap menurunnya tingkat kelulusan hidup lobster selama dalam kondisi transportasi. Kemasan dengan kepadatan 6 ekor/kotak plastik menghasilkan kelulusan hidup yang lebih baik dibandingkan dengan kemasan dengan kepadatan 8 ekor/kotak plastik. Semakin lama durasi dalam kondisi transportasi menyebabkan semakin menurunnya kelulusan hidup dan bobot lobster. Untuk menghindari resiko penurunan bobot serta mortalitas yang tinggi setelah pembugaran sebaiknya lobster tidak ditansportasikan lebih dari 6 hari dan kepadatan yang digunakan tidak lebih 6 ekor/kotak plastik. Dengan cara transportasi tersebut kelulusan hidup lobster dapat mencapai $97 \%$ dan tetap sehat setelah dibugarkan kembali. Transportasi sistem ini memungkinkan lobster diekspor ke berbagai negara dengan resiko kematian cukup kecil.

\section{DAFTAR PUSTAKA}

Anonymous. 2006a. Lobster FAQ. National marine fisheries service. Northeast fisheries science center. www/infoplease.com/ipa/A08454908.hml. diakses tanggal 1 April 2007. 5 pp.

Anonymous. 2006b . Cherax park aquaculture farm. http:/ /www.cheraxpark.com.au/export.html. Diakses tanggal 1 Maret 2007. 3 pp.

Anonymous. 2007. Pamona aquaculture. http:// www.pamonaqua.com.au/redclaw.html. Diakses tanggal 1 Maret 2007. 2 pp.
Ayres, P.A. and Wood, P.C. 1977. The Live Storage of Lobster. Lab Leaflet. MAFF Direct Fish Ress. Lowetoft. 37. 13 pp.

Bartelme, T.D. 2006. Marine Fish Acclimation Procedure. Pomancantus Publication. $6 \mathrm{pp}$.

Berka, R. 1986. The transportation of live fish. A Review. EIFAC Technical Paper, FAO. (48): 52 pp.

Goodrick, G.B., Paterson, B.D., and Grauf, S. Air transport of live kuruma Prawn (Paneus Japonicus) temperature control to improve survival. Food Australia. 45(8): 400-404.

Hastarini, E., Ikasari, D., dan Suryaningrum, T.D. 2006. Karakterisasi Media Kering sebagai Bahan Pengisi untuk Kemasan Lobster Air Tawar (Cherax quadricarinatus) Sistim Kering. Makalah disampaikan pada Diseminasi Teknologi Pengembangan Perikanan di Lampung 4-5 Desember 2006. 11 pp.

Ikasari, D., Suryaningrum,T.D., dan Syamdidi. 2008. Kajian fisiologis lobster air tawar pada suhu dingin sebagai dasar untuk transportasi hidup sistem kering. JPB Perikanan. 3(1): 45-54.

Itizawa, Y. 1990. Physiology of live fish in transportation. In Motohiro,T., Kadota, H., Hashimoto, K., Kayama, M., and Tokunaga, T. (eds). Science of Processing Marine Food Products. Japan International Cooperation Agency. Hyogo International Centre. p. 27-47.

Jeffs, A. 2003. The Potential for Crayfish Aquaculture in Northland. National Institute of Water and Atmospheric Research Ltd. Aukland, New Zealand. $15 \mathrm{pp}$.

Jones, C.M. 2001. Redclaw crayfish. In Jones, C.M. and Curtis, M. (eds.). A Handbook for Farmers and Investor. Freshwater Fisheries and Aquaculture Center, Walkamin. p. 127-133.

Lawrence, C. 2001. Yabbies (Cherax albidus). A Handbook for Farmers and Investors. Freshwater Fisheries and Aquaculture Center, Walkamin. 6 pp.

Morrissy, N.P., Walker, C., Fellows, and More, W. 2001. An Investigation of weight loss of Morron (Cherax fenuimanus) during live transportation to market. Western Australian Marine Research Laboratories. $2 \mathrm{pp}$.

Praseno, O. 1990. Cara Pengiriman/Transportasi Ikan Dalam Keadaan Hidup. Makalah disampaikan pada Temu Aplikasi Teknologi Pertanian Departemen Pertanian, Jakata. $15 \mathrm{pp}$.

Romero, X. and Murillo, P. 1997. Acclimation procedures for the Australian red claw crayfish, Cherax quadricarinatus. J. Applied Aquaculture. 7(4): 109-113.

Suryaningrum, T.D., Wibowo, S., Muljanah, I., Peranginangin, R., Hastarini, E., Syamdidi, dan Ikasari, D. 2006. Riset penanganan dan transportasi hidup ikan air tawar. Laporan Teknis Penelitian. Balai Besar Riset Pengolahan Produk dan Bioteknologi Kelautan dan Perikanan, Badan Riset Kelautan dan Perikanan, DKP. 126 pp. 
Suparno, Basmal, J., Muljanah, I., dan Wibowo, S. 1994. Pengaruh suhu dan waktu pembiusan dengan pendinginan bertahap terhadap ketahanan hidup udang windu tambak (Panaeus monodon) dalam transportasi sistem kering. J. Penel. Pasca Panen Perikanan. Balai Penel. Perikanan Laut, Jakarta. 79: 73-88.

Vijayakumaran, M. and Radhaskrishnan, E.V. 1997. Live transport and marketing of spiny lobster in India. Marine and Freshwater Research. 48(8): 823-828.

Wibowo, S., Suryaningrum, T.D., Muljanah, I., Peranginangin, R., Hastarini, E., Syamdidi, dan
Ikasari, D. 2005. Riset penanganan dan transportasi ikan hidup air tawar. Laporan Teknis Penelitian. Pusat Riset Pengolahan Produk dan Sosial Ekonomi Kelautan dan Perikanan, Badan Riset Kelautan dan Perikanan, DKP. $113 \mathrm{pp}$.

Wibowo, S., Setiabudi, E., Suryaningrum, T.D., dan Sudrajat, Y. 1994. Studi penggunaan metode penurunan suhu bertahap dalam transportasi sistem kering untuk lobster hijau pasir (Panulirus humarus). J. Penel. Pasca Panen Perikanan. Balai Penel. Perikanan Laut Jakarta. 79: 37-55. 